Journal of Advanced Research in Fluid Mechanics and Thermal Sciences

\title{
Addressing Visual Comfort Issues in Healthcare Facilities Using LED Lighting Technology - A Review on Daylighting Importance, Impact of Correlated Colour Temperature, Human Responses and Other Visual Comfort Parameters
}

\author{
Sivachandran R. Perumal ${ }^{1}$, Faizal Baharum ${ }^{1,}{ }^{*}$, Mohd Nasrun Mohd Nawi ${ }^{2}$ \\ School of Housing, Building \& Planning, Universiti Sains Malaysia, Pulau Pinang, Malaysia \\ School of Technology Management and Logistic, Universiti Utara Malaysia, Kedah, Malaysia
}

\section{ARTICLE INFO ABSTRACT}

\section{Article history:}

Received 11 October 2020

Received in revised form 7 February 2021

Accepted 15 February 2021

Available online 2 May 2021

\section{Keywords:}

LED Lighting; Healthcare; Occupant Visual Comfort; Human Response; Smart Lighting; Wound Recovery

\begin{abstract}
In the field of lighting technology, the choice of lighting has shifted from conventional incandescent and fluorescent to LED (Light Emitting Dode) lighting. Many businesses have yet to take full advantage of LED lighting technologies to address visual comfort problems for occupants. The current focus of installations and retrofitting jobs is only on dollar returns and energy-saving measures. By defining a range of vulnerabilities and discrepancies, this paper reviews the typical criteria affecting occupant visual comfort and shifts gear into those that are fundamental to healthcare setup. Issues such as the importance of daylight introduction into hospital wards and the benefits of choosing correct correlated colour temperature are discussed, among others discomforts. LED lighting technology has advanced immensely by offering flexibility to build a lighting system that meets the environmental requirements of the end-user. Lighting technology and approach are shifting to a new paradigm by focusing not only on vision but also human psychophysical wellbeing in interior spaces. A balance must exist between energy efficiency and visual comfort factors.
\end{abstract}

\section{Introduction}

Countries around the world are committed to reducing the detrimental impacts of climate change with the goal of reducing carbon emissions. The LED lighting application has become one of the essential energy-saving initiatives used by industries as it offers a quicker return on capital investments as nations become more aware of energy conservation efforts and sustainability. The LED lighting is rapidly used in industries to substitute conventional lighting either by retrofitting or replacing them. The concepts of energy efficiency and conservation applicable to LED lighting are widely recognised and very favourable [1-3]. Amongst the energy conservation measures, utilization of LED lighting technology for lighting and illumination purposes promised a faster return of investment, which appeals to industries that have 24-hour lighting applications. The emerging use of

\footnotetext{
* Corresponding author.

E-mail address: baharumfaizal@gmail.com
}

https://doi.org/10.37934/arfmts.82.2.4760 
LED lighting has also penetrated into the healthcare industries. Hospital wards, operating theatres, and other clinical rooms have been installed or retrofitted with LED lighting [4-7].

However, there is a point concern in occupant visual comfort being affected by the installed LED lighting analogous to the thermal comfort in air-conditioning's field of study. There are many methods to describe the definition of visual comfort for occupants. The 'non-annoyance-approach' emerging from the idea that 'comfort is no discomfort' is a generally accepted view. Occupant visual comfort is a subjective matter of interest. No one person may be satisfied with the comfort level of others [8]. In the healthcare sector, such as hospital wards, where patient rehabilitation or recovery time is crucial, it is also extremely necessary [9]. In modern days, the built environment of hospitals is in a more closed environment where the air circulated in buildings is regulated and conditioned. Similarly, lighting is also critical in closed settings to set the mood right for patients and employees by improving the 'healing-recovery-mood' and improve productivity for employees. Interior lighting colours on top of interior wall painting colours are often important to complement natural light as closely as possible to give patients a more relaxed feeling due to the design of the closed-building of hospitals [5].

Earlier researches utilized non-LED lighting for studies, most results are still applicable to LED lighting, since the fundamental lighting parameter measures are the same [8].

\section{Hypotheses \& Review Methodology}

This review paper's theme is to suggest that LED lighting has advantages in addressing healthcare facilities' visual comfort problems. The three hypotheses below pave the way for evaluating literature.

i. LED lighting technology has design versatility to meet the needs of end-user lighting, stressing visual comfort.

ii. LED lighting can create a conducive and efficient working environment through correct colour temperature combinations and lighting parameter settings.

iii. A health-friendly lighting environment within a healthcare facility will speed up the time of patient recovery.

Based on the above hypotheses, the approach of this review paper is to recognise the past and current shortcomings in both traditional lighting and LED lighting technology in order to correctly use it to close the gaps created by inadequate use of LED lighting that focuses only on energy saving. In the healthcare sector, therefore, motivating occupant comfort, namely visual comfort. Figure 1 demonstrates this paper's analysis methodology from a flow map. 


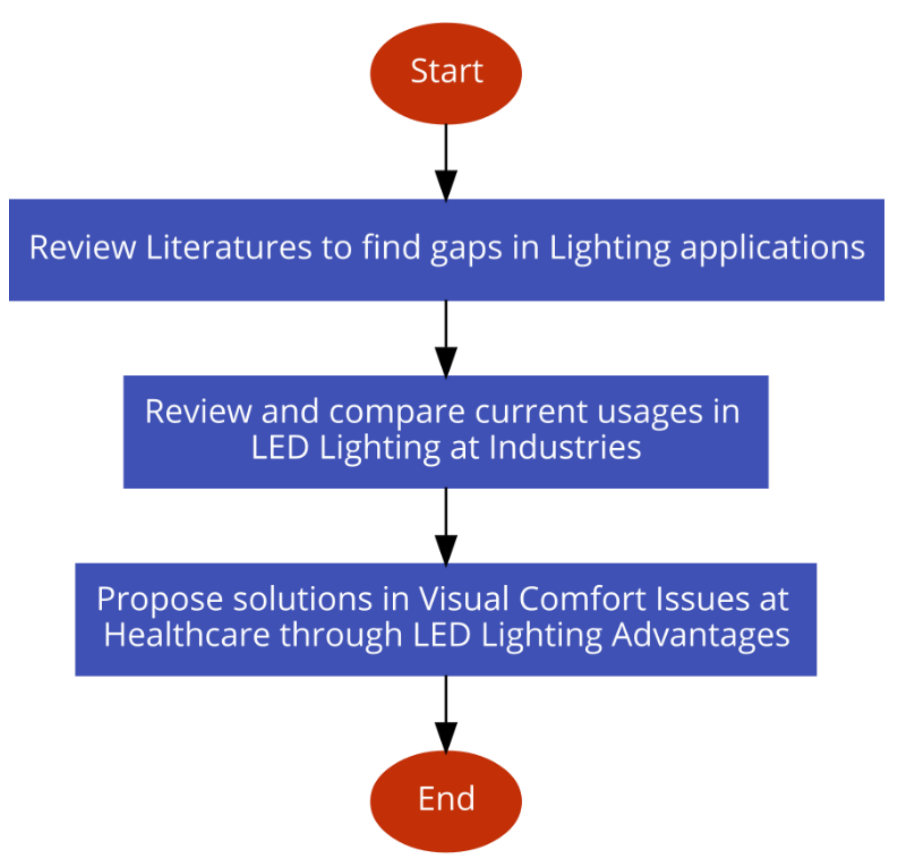

Fig. 1. Review Approach

The measures taken to obtain papers and journals concerning the topic of this paper are outlined in Figure 2 below. The references searched for are from the search tool provided by the library search tool of Universiti Sains Malaysia (USM). USM subscribes to articles indexed by the Scopus database. The Google Scholar database was a secondary search method to supplement the primary search, but the literature used is cross-mapped for credibility checking in the Scopus database. Keywords used for search criteria are as mentioned in the Keywords section. The search frequency is set to the degree that at least 5 relevant articles are included and 70\% should not be older than 2012. The search results were sorted according to relevance and thus filtered by the year published. However, fundamental books and guidelines, groundbreaking papers in the field of healthcare lighting, LED lighting, and daylighting have been referred also. 


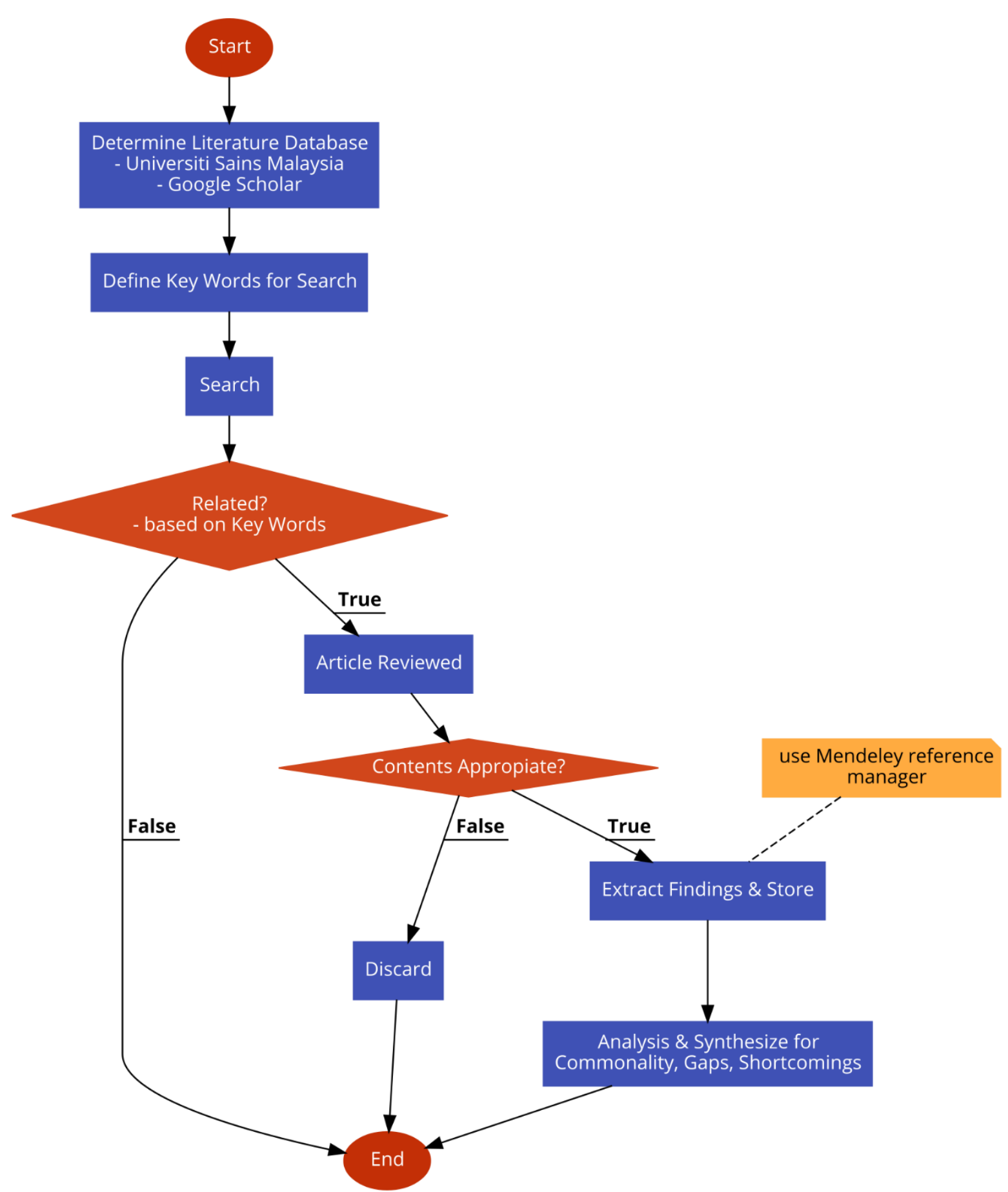

Fig. 2. Review Flow Chart

This review paper is arranged into a variety of subheadings. In order to identify differences in uncontrolled LED lighting use and traditional lighting applications, the subheadings are organised to achieve a suggestion of addressing visual comfort problems in healthcare through proper use of LED lighting technology. Table 1 below summarizes the search findings for each subheading confined by the keywords. 
Table 1

Search Summary

\begin{tabular}{|c|c|c|c|c|c|}
\hline $\begin{array}{l}\text { DATABASE: SCOPUS } \\
\text { Subheading } \\
\text { Search String }\end{array}$ & $\begin{array}{l}\text { Keywords } \\
\text { Restriction }\end{array}$ & $\begin{array}{l}\text { Articles } \\
\text { Found }\end{array}$ & $\begin{array}{l}\text { Articles } \\
\text { Reviewed }\end{array}$ & $\begin{array}{l}\text { Articles } \\
\text { Discarded* }\end{array}$ & $\begin{array}{l}\text { Remarks (Subject } \\
\text { Area) }\end{array}$ \\
\hline Lighting Quality & $\begin{array}{l}\text { Lighting, Human } \\
\text { Factors }\end{array}$ & 6715 & 10 & 6705 & $\begin{array}{l}\text { Engineering, } \\
\text { Environment, } \\
\text { Computer Science }\end{array}$ \\
\hline $\begin{array}{l}\text { Parameters Affecting } \\
\text { Visual Comfort }\end{array}$ & $\begin{array}{l}\text { Visual Comfort } \\
\text { Parameters, } \\
\text { Human, LED } \\
\text { Lighting }\end{array}$ & 29 & 9 & 20 & $\begin{array}{l}\text { Engineering, } \\
\text { Environment, } \\
\text { Computer Science }\end{array}$ \\
\hline Influence of Daylighting & Daylighting & 1827 & 18 & 1809 & $\begin{array}{l}\text { Engineering, Energy, } \\
\text { Environment, } \\
\text { Medicine, Social } \\
\text { Science }\end{array}$ \\
\hline $\begin{array}{l}\text { Lighting Requirements in } \\
\text { Healthcare Facilities }\end{array}$ & $\begin{array}{l}\text { Hospitals, } \\
\text { Architectural } \\
\text { Design }\end{array}$ & 23 & 12 & 11 & $\begin{array}{l}\text { Engineering, } \\
\text { Medicine, Social } \\
\text { Science, } \\
\text { Environment, } \\
\text { Nursing, Healthcare }\end{array}$ \\
\hline $\begin{array}{l}\text { Human Responses to } \\
\text { Lighting }\end{array}$ & Lighting, Standards & 949 & 5 & 944 & $\begin{array}{l}\text { Engineering, Social } \\
\text { Science, Medicine, } \\
\text { Environment, } \\
\text { Physiology }\end{array}$ \\
\hline $\begin{array}{l}\text { Lighting Requirements in } \\
\text { Medical Field }\end{array}$ & $\begin{array}{l}\text { Wound Healing, } \\
\text { Patient Recovery, } \\
\text { ALOS }\end{array}$ & 402 & 11 & 391 & $\begin{array}{l}\text { Engineering, Social } \\
\text { Science, Medicine, } \\
\text { Nursing }\end{array}$ \\
\hline $\begin{array}{l}\text { Humans Reaction to } \\
\text { Color Correlated } \\
\text { Temperature (CCT) } \\
\text { Parameter }\end{array}$ & Human, Color & 63 & 12 & 51 & $\begin{array}{l}\text { Engineering, } \\
\text { Environment }\end{array}$ \\
\hline $\begin{array}{l}\text { Glare Reduction in LED } \\
\text { Lighting }\end{array}$ & $\begin{array}{l}\text { LED Lighting, } \\
\text { Glare, Healthcare }\end{array}$ & 747 & 6 & 741 & Engineering \\
\hline $\begin{array}{l}\text { Flicker Reduction \& } \\
\text { Dimmable Character in } \\
\text { LED Lighting }\end{array}$ & $\begin{array}{l}\text { LED Lighting, } \\
\text { Flicker, Healthcare }\end{array}$ & 643 & 3 & 640 & Engineering \\
\hline $\begin{array}{l}\text { Illuminance, CRI, CQS, } \\
\text { Luminance Ratio, } \\
\text { Uniformities in LED } \\
\text { Lighting }\end{array}$ & $\begin{array}{l}\text { CRI, CQS, LED } \\
\text { Lighting }\end{array}$ & 332 & 10 & 322 & Engineering \\
\hline
\end{tabular}

*Note: Articles Discarded Due to Subject Area/Relevance/Age

\section{Lighting Quality}

A qualitative lighting measure is a matter of individual interest. Lighting quality is how good the light intensity is in each given room [12]. Lighting is quantified by agreed criteria in the scientific world, referring to recommendations and guidelines from international bodies [8]. The acceptability measure is subject to human requirements and experience [12]. For specific task performance and complex health-sustaining biological processes, humans need light. Since individuals spend more time indoors than outdoors, the provision of optimum lighting is necessary for any building [13]. Various sets of lighting parameter settings are required for distinct human tasks. A lighting intensity that is too high or low for a particular task can present users with discomfort. The standard of lighting depends on the degree at which the lighting produced meets the intentions and limits set by the 
client and the designer. The design, however, must also comply with the agreed guidelines to be within the limits $[1,8,14,15]$. On the other hand, poor lighting quality affects the retina, induces headaches and leads to stressful working conditions [1,8,10,16-19].

\section{Parameters Affecting Visual Comfort}

The human body is a complex biological system composed of several organs and interconnections, but it is a fascinating topic for scientists to thoroughly explore and comprehend. The vision system is one of the main systems throughout this system since it helps people to see. Seeing is one of the human body's main sensory mechanisms. The physiological processes of the body transmit signals of pain to the brain if it feels pain from external sources $[1,2,4,11]$. A person can feel defined symptoms in the sense of the vision system, which is understood and assessed with subjective studies such as the following [8].

Vision Discomfort Symptoms:

i. Glare

ii. Difficulty in doing a visual task (e.g., identifying colour-coded electronic components)

iii. Annoyance

iv. Stress

v. Physical symptoms like:

- Headaches

- Pains

- Sore

- Itchy, watering eyes

- Nausea

- Others

Therefore, comfortable lighting in a setting can be described as a space in which lighting does not cause discomfort by evaluating the symptoms of discomfort.

Various experiments to quantitatively assess and model visual comfort have been carried out over time. The texts, guidelines on lighting environments and related studies of the International Commission on Illumination (CIE) recognise the following requirements as necessary for visual comfort in indoor lighting, as follows $[1,8,17,20,21]$.

i. Glare (from luminaires, daylight, bright surfaces like windows)

ii. Veiling reflections (reflections from work plane)

iii. Illuminance levels (work plane, surrounding)

iv. Luminance ratios and uniformities

v. Colour rendering index (CRI) \& Colour Quality Scale (CQS)

vi. Correlated Color Temperature (CCT)

vii. Flicker

From an architectural point of view, for task performance analysis relating to lighting, researchers often consider indoor building properties, as follows [22].

i. Space and room appearance

ii. Surfaces brightness and colour

iii. Light distribution

iv. The appearance of light and luminaires 
Such structural characteristics are important because they affect indoor lighting by further amplifying or attenuating the spread and reach of the lighting in a room [19].

\section{Influence of Day Lighting}

Daylighting plays a pivotal role in the daily execution of human tasks in the context of the built environment. The excellent introduction of daylight into a building results in improved specific task performance, especially in schools and office buildings [17,18,23-26].

Some of the basic lighting design criteria in a healthcare setting are as follows $[13,19,26]$.

i. Visibility of patients from nurse stations and vice versa

ii. Safeguarding patients' privacy

iii. Providing low noise levels

iv. Patient self-control of environment

v. Design to allow for natural light and views

vi. Allocating space and comfort for visitors

Light is a necessary component for safe and effective healthcare facilities that promote patient health and well-being, whether natural or artificial. Daylight and outdoor views are essential ingredients that contribute to patient healing and recovery in healthcare wards [13]. For ease of movement, the design of hospital wards should be such that the floor would be able to receive an average illuminance of $150 \mathrm{~lx}$. All have been shown to have a major effect on our wellbeing and our ability to combat infection or recover from treatment by being in a state of well-being, in a pleasant atmosphere, and obtaining good quality light, artificial or natural [13]. In hospital buildings, the conditions of inhabitants can be greatly improved if sufficient light levels are given for safe travel inside buildings, to help diagnosis, care and rehabilitation. It helps to reduce stress and decrease medical errors with sufficient lighting $[5,22,35,36]$.

"Daylight inspires, invigorates, and has a positive influence on the body and mind" [37]. Natural light exposure decreases patient distress, minimises discomfort, shortens hospital stays, improves the ability to perform visual tasks and improves sleep [14,18,24].

There is data showing that indoor lighting correlates with comfort for occupants. People enjoy sunshine more and prefer to be located closer to windows $[18,27]$. In daylit workplaces, the literature on occupant preferences and satisfaction with the luminous atmosphere and control systems showed a clear strong liking for daylight [25].

It favours the energy efficiency approach by implementing daylighting in houses, which in turn decreases $\mathrm{CO}_{2}$ emissions to the atmosphere and buildings [19,28-30]. The increased $\mathrm{CO}_{2}$ content in buildings appears to make occupants less focused on the task at hand, thus reducing performance.

In hospitals, the amount of daylight depends on the ward layout and the window number, size, and location. In the design of hospital buildings, a minimum average daylight factor of $3 \%$ should be reached where possible [26].

To calculate the necessary daylight for building space, the relation between daylight penetration into a building space with the height property of the exterior window, assisted by models and calculations, is used. The distance (D) that daylight can reach inside a building is normally two and a half times the height $(H)$ of the window $(D=2.5 H)[19]$.

The Average Length of Stay (ALOS) of patients in a healthcare facility is reduced for patient wards/beds on the eastern side of the hospital. Daylight, as associated with sunlight, rises in the east and sets in the west [26]. Therefore, the rate of change in the bed occupancy rate has also risen, indicating more admission to the patient ward at a time with a greater workload. 
One of the factors depriving the sleep of a patient is the environment of the wards. To allow patients to rest or sleep, nurses turned on the warm-coloured downlights in hospital wards [31]. The significance of rest and sleep for patient recovery will be further explored in the Lighting Requirements in the Medical Field section.

Daylighting connects patients to the outside world, which is an essential element of natural healing since patients spend more time in healthcare wards. Thus, the design of hospital lighting shall be able to cater for therapeutic lighting levels, sourced from ambient outdoor lighting [36].

LED lighting technology has the potential to mimic, but not $100 \%$, to a certain extent to satisfy the requirements of ambient daylighting [2,5,17,24,32-34].

\section{Lighting Requirements in Bio-Medical Field}

The human body is mainly exposed to light through the skin and eyes [12]. Lighting light to the skin, which assists in healing, has medical benefits $[26,38,39]$. A healing environment is one that has a nurturing and therapeutic effect.

A well-designed hospital setting can reduce the anxiety and stress of patients, speed up recovery, shorten hospitalizations, decrease medication usage, reduce discomfort, and promote a sense of well-being [13]. In the context of the visual comfort of lighting in the rehabilitation of patients, the proper implementation of LED lighting gives healthcare professionals the ability to recover patients more efficiently and cure specific diseases [3,4,11,26,39].

A large scale study conducted by a team of researchers studied the correlation between the appropriate lighting level and the reduction of medication dispensing error rates. They found that medication dispensing error rates were significantly lower at an illumination level of 1,500 lux (2.6\%) than those of 450 lux (3.8\%) [40].

Sleep deficiency and deprivation are root-caused to be a common underlying mechanism in causing cardiovascular diseases related to endothelial dysfunction. Patients in hospital wards need sufficient sleep and rest for recovery without exaggerating current illnesses $[31,41]$.

A clinical experiment to establish the link between the wound healing rate by daytime and nighttime variable suggests wounds recovered $60 \%$ faster during the daytime proving circadian regulation of the human cytoskeleton influences wound-healing efficacy [42]. Sleep restriction delayed local immune response and skin barrier restoration with and without "multi-nutrient" nutrition intervention. Thus, underscoring the importance of adequate sleep when feasible for patient recovery.

LEDs are not only the solution for biological studies but also for health caring projects. Numerous studies conducted to investigate the effects of LEDs on plants such as elongation, axillary shoot formation, leaf anatomy, and rhizogenesis as well as on animals such as cellular proliferation, collagen synthesis, growth factor metabolism in cells, cell growth enhancement, and cancer treatment shows beneficial results [35].

\section{Humans Reaction to Color Correlated Temperature (CCT) Parameter}

The human visual system's dynamic range encompasses a wide luminance range from $10-3 \mathrm{~cd} / \mathrm{m}^{2}$ to $106 \mathrm{~cd} / \mathrm{m}^{2}$. Vision may be categorised simply as three forms, i.e., photopic vision, scotopic vision, and mesopic vision, according to the change in surrounding luminance [43]. Mesopic vision occurs is when the retina region is activated by low lighting or dimmed field. Higher values are associated with white-blue-ish or cooler colours in the Correlated Color Temperature (CCT) continuum, whereas lower CCT represents a warmer or yellow-light-ish ambience. The appearance of lighting is the CCT 
of light. In another experiment, the former hypothesis is further endorsed to test the influence of lighting colours on human task performance but instead focuses only on mesopic vision $[44,45]$. The findings were consistent with the fact that the response time of humans to a concerted physical activity in a room differs at various CCT extremes. In completing tasks at lower values of CCTs, test subjects were slower compared to higher CCTs. The CCT spectrum associated with its colours is shown in Figure 3.

WARM

$\mathrm{COOL}$

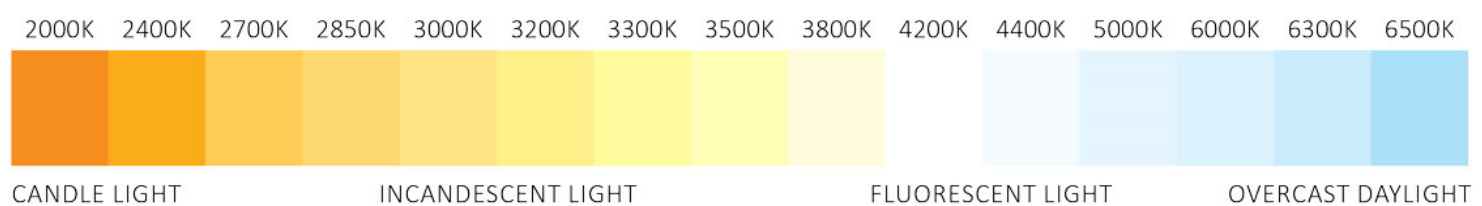

Fig. 3. Correlated Color Temperature [46]

High CCT (17000 K) lighting in office buildings tends to enhance the well-being, functioning and efficiency of study participants in research carried out in a shift-working call centre [47]. One approach used to assess a subject's fatigue level was by circulating survey questionnaires based on the syndrome-specific instrument, i.e. the Columbia Jet Lag scale, to show that blueish light has contributed to improved alertness, lower sleepiness during the day, and better performance at work [47].

However, a study shows that relaxation and brainwave stability are not guaranteed when the colour temperature is low, by varying the effect of CCT on the task performance of school-age children and brainwaves. Attention and cognitive ability are not necessarily more inherent when the colour temperature is high, as biological and emotional factors are often influenced. Nevertheless, when performing specific tasks, the colour temperature changes encouraged emotional variables rather than brainwave, a biological improvement. Although the biological shift to lighting parameters is prevalent, the paper provided concrete evidence that students were in a calming mood at lower CCTs. Students were alert at the other higher extreme of CCT [44].

The presence of blue light in indoor environments does not encourage a human being to relax or sleep, particularly at night. Sleep is stimulated by the presence of warm-yellow light. An experiment performed on human subjects to methodologically prove the hypothesis that lighting colours influence human responses deduced the validity of this theory produced by the previous papers [48]. Initially subjected to a controlled stress test, called MIST, human subjects were later sent to recovery rooms illuminated with a blue light test case and a controlled natural white light case. In a shorter time compared to the blue light-lit room, the human participants emerging from the white-light illuminated rooms relaxed earlier. EEG and ECG readings, which reflect stress levels in terms of heart rate $(H R)$ and relative gamma $(R G)$, were the parameters used to test human responses. The ratio of power between brain rhythms is RG. Participants recovered three times faster than the others in the blue light lit room.

As colours play an important role in facilitating visual comfort for occupants, another paper further explores the effects of improvement in post-stress human responses in a colour-controlled space [49]. In order to test the alertness in human samples, two factors were mainly varied, i.e. the spatial colours and colours of lighting production. A stress test matrix questions, namely, Behavioral Risk Factor Surveillance System (BRFSS), Stress Arousal Checklist (SACL), Building Occupant 
Satisfaction Survey for Healthcare Settings, General Stress, and Comfort Questions, were used. The test subjects became more responsive, post-stress to higher CCTs.

Spatial colours, such as wall paint colours, are selected architecturally by interior design, while LED lighting works to control lighting colours. Conventional lighting might be able to do this, but to constitute distinct CCT ranges, it would incur higher costs and more comprehensive electronic circuitry and fixture sizes.

By using RGB LEDs coupled with electronics, LED lighting technology has the benefit of varying the CCT of the lighting fixture. In an experiment, a mood algorithm for occupant visual comfort provided a desired ambient lighting. The lighting was modulated using image processing coding and outputted to an LED lighting RGB fixture [50]. The results were positive, in which humans responded positively to the various moods and environments settings. In the test subjects, sleepiness and rest were induced by relaxation. The popularity of this application means that it provides an opportunity for patients and healthcare providers to add visual relaxation and therefore efficiency in the healthcare setup.

The human emotional or biological characteristics of lighting CCT are yet to be mathematically modelled, as the variance associated with various individuals is big. The effect of colour temperature on comfort and indoor lighting preference indicates that lighting CCT has an influence on comfort in indoor environments for people/occupants $[9,26,39,50]$. These results provide an opportunity to use LED lighting technologies to boost occupant productivity and patient recovery time in the healthcare setup.

\section{Visual Glare Reduction in LED Lighting}

Unified Glare Rating (UGR) and Visual Comfort Probability (VCP) are two technical parameters associated with visual glare measurement $[8,20,51]$. When experimenting with a portable inspection device in a test space to estimate direct glare from different LED modules, the glare measurement was comparatively smaller compared to traditional lighting. LED lighting modules are unidirectional, which supports the results. Thus, unidirectional lighting through LED lighting technology presents an opportunity to focus on human task performance [24,52]. Task performance in healthcare setup ranges from laboratory tests to clinical examination to surgeries by clinicians.

Glares from lighting fixtures, by changing lateral angles, may also be physically corrected. However, by using LED lighting, this trial and error method can be avoided [53]. Glares are unnecessary lighting characteristics in a healthcare setup, as they can prevent medical practitioners from making an accurate diagnosis. The unidirectional property of LED lighting presents an opportunity to reduce glares to occupants in the vicinity of the illuminated area. By installing LED lamps in a recessed manner, one may further minimise glare. The glares are not apparent in the above design method until the occupant is essentially below the illumination, looking straight up into the fixture. In addition, as glare is a discomfort, it will be difficult for patients to relax or fall asleep.

\section{Flicker Reduction \& Dimmable Character in LED Lighting}

When the lighting intensity differs with time, a lighting source is said to flicker. Flicker often happens if there is relative motion between the source of illumination and the observer. Conventional lighting runs on alternating current (AC) mains supply, which varies with time $(50 \mathrm{~Hz}$ or $60 \mathrm{~Hz}$ ). Due to this time-varying source, the light output follows the same to switch on and off which, causes flicker. Flicker in lighting has the potential to trigger seizures, migraines, headaches, and maybe visually uncomfortable or a persistent distraction $[1,21]$. In the healthcare setup, flickers are 
undesirable for apparent health concerns. A transformer is used in the early days to power LED lighting from the AC mains supply, which has a downside of adding flicker LED lighting. The transformers were used to step down the mains voltages in LED lighting drivers. Today, with the developments in power electronics technology, direct current (DC) source drives LED lighting. The DC source driver can remove flickers at the lighting output and prove to be helpful to nursing homes and thus to the healthcare facility [54]. The ability to dim the brightness of the lighting in hospital wards is important, as it helps to set the mood for sleep and rest for patients. Older analogue-dimmer technologies also cause flickers to occur. However, the flicker disadvantage is lowered to acceptable levels by controlling DC source-driver modulation (Pulse Width Modulation) in LED lighting by maintaining the optimum dim intensity [1].

\section{Illuminance, CRI, CQS, Luminance Ratio, Uniformities in LED Lighting}

Illuminance is the total luminous flux projected on a surface, per unit area. Luminous flux is a measure of the total amount of energy radiated per second from a light source in all directions. An observer perceives illuminance as brightness, which may not be measured objectively [1]. The LED lighting modules have capabilities to match incandescent or fluorescent lighting's illuminance or even higher [50,53]. Medical examination lighting or even operating room lighting require higher illuminance for better visibility and visual acuity $[4,5]$.

The Colour Rendering Index (CRI) and the Colour Quality Scale (CQS) provide systems for calculating the quality of lighting. The CRI metric $R_{a}$ is an average score based on how well the illuminant renders the first eight colour samples in the CRI system [1]. It is the primary measure of colour rendering properties. In order to distinguish tissue colours during wound evaluation, healthcare providers need high CRI lighting, especially in operating rooms, for example. The LED lighting can provide this criterion $[9,39,55]$.

The luminance ratio is the measure of differentiating between two illuminance sources. The luminance ratio allows the lighting luminance to remain in appropriate proportions for a static task performer. It prevents glaring situations caused by a substantial contrast, hence impairing visual performances. Whereas, lighting uniformities is a measure of task area lighting to the surrounding area. Both these parameters are crucial to the healthcare provider. An area that is too uniformly lit decreases alertness and causes people to get tired more easily. Both these parameters would be beneficial to healthcare providers such as in laboratories and pharmacies $[5,22,36]$.

\section{LED Lighting Technology: The Way Forward in Healthcare}

The cost of capital for investment in LED lighting is higher, but when it comes to comfort and protection, costs can come in second. LED lighting offers an opportunity to refine the ambient lighting requirements to accommodate patients and the healthcare staff and their form of the disease for faster recovery. There will be favourable outcomes of more dialogue with healthcare professionals. There is a return on investment period for any energy-saving measure implemented. Via power bill reduction, patients recovering quicker, and workers being efficient, the capital cost will be recovered. Higher change in Bed Occupancy Rates (BOR) implies that patient admission and discharge are rapidly increasing, highlighting productivity.

For daylight implementation, healthcare facilities face an obstacle, such as in operating theatres (OT) and recovery rooms, where such rooms are in a closed environment. This issue may be solved using LED lighting technology. In addition, LED technology, such as OT lights and exam lights, has already been incorporated into biomedical equipment that uses light sources. 
The use of LED lighting in the healthcare industry is safe, arising from numerous LED lighting studies, such as schools and offices. Using the micro-electronics developments and design versatility of LED lighting, the gaps and shortcomings in the supply of quality lighting to test spaces can be solved. Applications shall, however, be governed and managed in accordance with the requirements available that are accepted worldwide. In a nutshell, LED lighting is the way forward for lighting, energy efficiency, and visual comfort problems for occupants.

\section{Acknowledgement}

The authors would like to thank the Ministry of Health, Malaysia, and University Sains Malaysia for making available the Short-term Grant (304/PPBGN/6313115) and study scholarship, respectively, for this paper to be published.

\section{References}

[1] Price, L. L. A., M. Khazova, and J. B. O'Hagan. "Human Responses to Lighting based on LED Lighting Solutions." CRCERDD 01-2016, Public Health England, 2016.

[2] Pandharipande, Ashish, and Guy R. Newsham. "Lighting controls: Evolution and revolution." Lighting Research \& Technology 50, no. 1 (2018): 115-128. https://doi.org/10.1177/1477153517731909

[3] Lorenzi, Neal. "Illuminating Trends. LED Systems Expand Reach and Efficiency." Health Facilities Management 26, no. 5 (2013): 45-48.

[4] Johnston, Penny. "Helpful Hues: The Role of Color in Health Care Lighting." Health Facilities Management 24, no. 9 (2011): 30-33.

[5] Ferenc, Jeff. "Lighting the way. New illumination products offer multiple benefits." Health Facilities Management 24, no. 2 (2011): 32-36.

[6] Hickerson, Eddie. "Shine on. New lighting control technologies increase efficiencies and lower costs." Health Facilities Management 23, no. 8 (2010): 17-20.

[7] Lorenzi, Neal. "Lighting it up. LED fixture manufacturers target health care facilities." Health Facilities Management 25, no. 5 (2012): 32-36.

[8] lacomussi, Paola, Michela Radis, Giuseppe Rossi, and Laura Rossi. "Visual comfort with LED lighting." Energy Procedia 78 (2015): 729-734. https://doi.org/10.1016/i.egypro.2015.11.082

[9] Macleod, Lauren. "Lighting it up: Tunable white light adds to patient conmfort and well-being. Lighting it up." Health Facilities Management 29, no. 7 (2016): 29-33.

[10] Das, Sutapa. "Lighting and health of building occupants: a case of Indian information technology offices." Current Science (2015): 1573-1580.

[11] Zind, Tom. "The Human-Centric Lighting Debate." EC\&M, April 16, 2018. https://www.ecmweb.com/lightingcontrol/article/20903500/the-humancentric-lighting-debate.

[12] Boyce, Peter Robert. Human Factors in Lighting, Second Edition. CRC Press, London, 2003. https://doi.org/10.1201/9780203426340

[13] Ulrich, Roger S., Craig Zimring, Xuemei Zhu, Jennifer DuBose, Hyun-Bo Seo, Young-Seon Choi, Xiaobo Quan, and Anjali Joseph. "A review of the research literature on evidence-based healthcare design." HERD: Health Environments Research \& Design Journal 1, no. 3 (2008): 61-125. https://doi.org/10.1177/193758670800100306

[14] Boyce, Peter R. "Lighting quality: The unanswered question." In Proc. of First CIE Symposium on Lighting Quality, pp. 72-84. 1998.

[15] Huang, Ying. "Impact of Green Building Design on Healthcare Occupants---with a Focus on Healthcare Staff." In Masters Abstracts International, vol. 49, no. 05. 2011.

[16] Sithravel, RatnaKala, Rahinah Ibrahim, Munn Sann Lye, Enoch Kumar Perimal, Normala Ibrahim, and Nur Dalilah Dahlan. "Morning boost on individuals' psychophysiological wellbeing indicators with supportive, dynamic lighting in windowless open-plan workplace in Malaysia." PloS One 13, no. 11 (2018): e0207488. https://doi.org/10.1371/journal.pone.0207488

[17] Xuan, Xiaodong. "Study of indoor environmental quality and occupant overall comfort and productivity in LEEDand non-LEED-certified healthcare settings." Indoor and Built Environment 27, no. 4 (2018): 544-560. https://doi.org/10.1177/1420326X16684007

[18] Collins, Belinda Lowenhaupt. Evaluation of subjective response to lighting distributions: a literature review. Building and Fire Research Laboratory, National Institute of Standards and Technology, 1993.

[19] Nimlyat, Pontip Stephen. "Patient's Satisfaction Of Indoor Environmental Quality In Hospital Wards In Jos Nigeria." 
PhD diss., Universiti Teknologi Malaysia, 2016.

[20] BS EN 12464-1:2011. Light and lighting. Lighting of work places. Indoor work places. BSI Standard Publication, 2011.

[21] Kitsinelis, Spiros, Georges Zissis, and Lydie Arexis-Boisson. "A study on the flicker of commercial lamps." Light \& Engineering 20, no. 3 (2012): 25-33.

[22] Huisman, Emelieke RCM, Ernesto Morales, Joost van Hoof, and Helianthe SM Kort. "Healing environment: A review of the impact of physical environmental factors on users." Building and Environment 58 (2012): 70-80. https://doi.org/10.1016/i.buildenv.2012.06.016

[23] Naves David Amorim, Cláudia. "Opinion: Sustainability and daylighting-a local issue?." Lighting Research \& Technology (2018): 658-659. https://doi.org/10.1177/1477153518787731

[24] Hua, Ying, Anne Oswald, and Xiaodi Yang. "Effectiveness of daylighting design and occupant visual satisfaction in a LEED Gold laboratory building." Building and Environment 46, no. 1 (2011): 54-64. https://doi.org/10.1016/i.buildenv.2010.06.016

[25] Galasiu, Anca D., and Jennifer A. Veitch. "Occupant preferences and satisfaction with the luminous environment and control systems in daylit offices: a literature review." Energy and Buildings 38, no. 7 (2006): 728-742. https://doi.org/10.1016/j.enbuild.2006.03.001

[26] Choi, Joon-Ho, Liliana O. Beltran, and Hway-Suh Kim. "Impacts of indoor daylight environments on patient average length of stay (ALOS) in a healthcare facility." Building and Environment 50 (2012): 65-75. https://doi.org/10.1016/j.buildenv.2011.10.010

[27] Heerwagen, Judith H., and Gordon H. Orians. "Adaptations to windowlessness: A study of the use of visual decor in windowed and windowless offices." Environment and Behavior 18, no. 5 (1986): 623-639. https://doi.org/10.1177/0013916586185003

[28] Fei, Li, Suocheng Dong, Li Xue, Quanxi Liang, and Wangzhou Yang. "Energy consumption-economic growth relationship and carbon dioxide emissions in China." Energy Policy 39, no. 2 (2011): 568-574. https://doi.org/10.1016/i.enpol.2010.10.025

[29] Soon, Willie, Sallie L. Baliunas, Arthur B. Robinson, and Zachary W. Robinson. "Environmental effects of increased atmospheric carbon dioxide." Climate Research 13, no. 2 (1999): 149-164. https://doi.org/10.3354/cr013149

[30] Hardisty, Paul E., Tom S. Clark, and Robert G. Hynes. "Life cycle greenhouse gas emissions from electricity generation: A comparative analysis of Australian energy sources." Energies 5, no. 4 (2012): 872-897. https://doi.org/10.3390/en5040872

[31] Salzmann-Erikson, Martin, Linda Lagerqvist, and Sandra Pousette. "Keep calm and have a good night: nurses' strategies to promote inpatients' sleep in the hospital environment." Scandinavian Journal of Caring Sciences 30, no. 2 (2016): 356-364. https://doi.org/10.1111/scs.12255

[32] Kumar, Arun, Pushpendu Kar, Rakesh Warrier, Aditi Kajale, and Sanjib Kumar Panda. "Implementation of smart LED lighting and efficient data management system for buildings." Energy Procedia 143 (2017): 173-178. https://doi.org/10.1016/i.egypro.2017.12.667

[33] Avcı, Ayşe Nihan, and İpek Memikoğlu. "Effects of LED Lighting on Visual Comfort with Respect to the Reading Task." International Journal of Electrical and Computer Engineering 11, no. 8 (2017): 974-978.

[34] Chew, Ivan, Dilukshan Karunatilaka, Chee Pin Tan, and Vineetha Kalavally. "Smart lighting: The way forward? Reviewing the past to shape the future." Energy and Buildings 149 (2017): 180-191. https://doi.org/10.1016/i.enbuild.2017.04.083

[35] Nhut, Duong Tan, and Nguyen Ba Nam. "Light-emitting diodes (LEDs): an artificial lighting source for biological studies." In The third international conference on the development of biomedical engineering in Vietnam, pp. 134139. Springer, Berlin, Heidelberg, 2010. https://doi.org/10.1007/978-3-642-12020-6 33

[36] Boubekri, Mohamed. Daylighting, architecture and health: building design strategies. Routledge, 2008. https://doi.org/10.4324/9780080940717

[37] Köster, Helmut. Dynamic daylighting architecture: basics, systems, projects. Springer Science \& Business Media, 2004.

[38] Smith, Tracey J., Marques Wilson, J. Philip Karl, Jeb Orr, Carl Smith, Adam Cooper, Kristin Heaton, Andrew J. Young, and Scott J. Montain. "Impact of sleep restriction on local immune response and skin barrier restoration with and without "multinutrient" nutrition intervention." Journal of Applied Physiology 124, no. 1 (2018): $190-200$. https://doi.org/10.1152/japplphysiol.00547.2017

[39] Bartczak, Piotr, Ana Gebejes, Pauli Fält, and Markku Hauta-Kasari. "An LED-based tunable illumination for diverse medical applications." In 2016 IEEE 29th International Symposium on Computer-Based Medical Systems (CBMS), pp. 292-293. IEEE, 2016. https://doi.org/10.1109/CBMS.2016.33

[40] Buchanan, T. L., K. N. Barker, J. T. Gibson, and B. C. Jiang. "Illumination and errors in dispensing." American Journal of Hospital Pharmacy 48, no. 10 (1991): 2137-2145. https://doi.org/10.1093/ajhp/48.10.2137

[41] Kohansieh, Michelle, and Amgad N. Makaryus. "Sleep deficiency and deprivation leading to cardiovascular disease." 
International Journal of Hypertension 2015 (2015). https://doi.org/10.1155/2015/615681

[42] Hoyle, Nathaniel P., Estere Seinkmane, Marrit Putker, Kevin A. Feeney, Toke P. Krogager, Johanna E. Chesham, Liam K. Bray et al. "Circadian actin dynamics drive rhythmic fibroblast mobilization during wound healing." Science Translational Medicine 9, no. 415 (2017). https://doi.org/10.1126/scitranslmed.aal2774

[43] Dong, Lili, Li Qin, Wenhai Xu, and Lidong Zhang. "The impact of LED correlated color temperature on visual performance under mesopic conditions." IEEE Photonics Journal 9, no. 6 (2017): 1-16. https://doi.org/10.1109/JPHOT.2017.2760257

[44] Park, YunHee. "Color temperature's impact on task performance and brainwaves of school-age children." Journal of Physical Therapy Science 27, no. 10 (2015): 3147-3149. https://doi.org/10.1589/ipts.27.3147

[45] Burattini, Chiara, Laura Piccardi, Giuseppe Curcio, Fabio Ferlazzo, Anna Maria Giannini, and Fabio Bisegna. "Cold LED lighting affects visual but not acoustic vigilance." Building and Environment 151 (2019): 148-155. https://doi.org/10.1016/i.buildenv.2019.01.022

[46] Zumtobel. The Lighting Handbook: your concise reference book - 5th Edition. PEFC, 2017.

[47] Mills, Peter R., Susannah C. Tomkins, and Luc JM Schlangen. "The effect of high correlated colour temperature office lighting on employee wellbeing and work performance." Journal of Circadian Rhythms 5, no. 1 (2007): 1-9. https://doi.org/10.1186/1740-3391-5-2

[48] Minguillon, Jesus, Miguel Angel Lopez-Gordo, Diego A. Renedo-Criado, Maria Jose Sanchez-Carrion, and Francisco Pelayo. "Blue lighting accelerates post-stress relaxation: Results of a preliminary study." PloS One 12, no. 10 (2017): e0186399. https://doi.org/10.1371/journal.pone.0186399

[49] Gray, Whitney Austin, Karen S. Kesten, Stephen Hurst, and Laura Anderko. "Using clinical simulation centers to test design interventions: a pilot study of lighting and color modifications." HERD: Health Environments Research \& Design Journal 5, no. 3 (2012): 46-65. https://doi.org/10.1177/193758671200500306

[50] Kim, Yong Hwi, Yong Yi Lee, Bilal Ahmed, Moon Gu Son, Junho Choi, Jong Hun Lee, and Kwan H. Lee. "MudGet: Reproduction of the desired lighting environment using a smart-LED." Journal of Computational Design and Engineering 4, no. 3 (2017): 231-237. https://doi.org/10.1016/i.jcde.2017.02.006

[51] Chen, Po-Li, Chun-Hsiang Liao, Hung-Chung Li, Shyh-Jye Jou, Han-Ting Chen, Yu-Hsin Lin, Yu-Hsiang Tang et al. "A portable inspection system to estimate direct glare of various LED modules." In International Conference on Optical and Photonic Engineering (icOPEN 2015), vol. 9524, p. 95241X. International Society for Optics and Photonics, 2015. https://doi.org/10.1117/12.2189599

[52] Lin, Yandan, Yihong Liu, Yaojie Sun, Xiaoyan Zhu, Jushui Lai, and Ingrid Heynderickx. "Model predicting discomfort glare caused by LED road lights." Optics Express 22, no. 15 (2014): 18056-18071. https://doi.org/10.1364/OE.22.018056

[53] Chitnis, Dipti, H. C. Swart, and S. J. Dhoble. "Escalating opportunities in the field of lighting." Renewable and Sustainable Energy Reviews 64 (2016): 727-748. https://doi.org/10.1016/i.rser.2016.06.041

[54] Taylor, Alma EF. "Illumination fundamentals." Lighting Research Center, Rensselaer Polytechnic Institute (2000).

[55] Van Hoof, J., A. C. Westerlaken, M. P. J. Aarts, E. J. M. Wouters, A. M. C. Schoutens, M. M. Sinoo, and M. B. C. Aries. "Light therapy: methodological issues from an engineering perspective." Technology and Health Care 20, no. 1 (2012): 11-23. https://doi.org/10.3233/THC-2011-0650 